University of Nebraska - Lincoln

DigitalCommons@University of Nebraska - Lincoln

Phosphate Imposed Limitations on Biological Reduction and Alteration of Ferrihydrite

Thomas Borch

Stanford University, borch@colostate.edu

Yoko Masue

Stanford University

Ravi K. Kukkadapu

Pacific Northwest National Laboratory, ravi.kukkadapu@pnl.gov

Scott Fendorf

Stanford University, fendorf@stanford.edu

Follow this and additional works at: https://digitalcommons.unl.edu/usdoepub

Part of the Bioresource and Agricultural Engineering Commons

Borch, Thomas; Masue, Yoko; Kukkadapu, Ravi K.; and Fendorf, Scott, "Phosphate Imposed Limitations on Biological Reduction and Alteration of Ferrihydrite" (2007). US Department of Energy Publications. 148. https://digitalcommons.unl.edu/usdoepub/148

This Article is brought to you for free and open access by the U.S. Department of Energy at DigitalCommons@University of Nebraska - Lincoln. It has been accepted for inclusion in US Department of Energy Publications by an authorized administrator of DigitalCommons@University of Nebraska - Lincoln. 


\section{Phosphate Imposed Limitations on Biological Reduction and Alteration of Ferrihydrite}

THOMAS BORCH, ${ }^{*},{ }^{\dagger}, \S$ YOKO MASUE, ${ }^{\dagger}$

RAVI K. KUKKADAPU, ${ }^{\ddagger}$ AND

S C O T T FENDOR F*, †

Department of Geological and Environmental Sciences, Stanford University, Stanford, California 94305, and Pacific

Northwest National Laboratory, Richland, Washington 99352

Biogeochemical transformation (inclusive of dissolution) of iron (hydr)oxides resulting from dissimilatory reduction has a pronounced impact on the fate and transport of nutrients and contaminants in subsurface environments. Despite the reactivity noted for pristine (unreacted) minerals, iron (hydr)oxides within native environments will likely have a different reactivity owing in part to changes in surface composition. Accordingly, here we explore the impact of surface modifications induced by phosphate adsorption on ferrihydrite reduction by Shewanella putrefaciens under static and advective flow conditions. Alterations in surface reactivity induced by phosphate changes the extent, decreasing $\mathrm{Fe}(\mathrm{III})$ reduction nearly linearly with increasing $P$ surface coverage, and pathway of iron biomineralization. Magnetite is the most appreciable mineralization product while minor amounts of vivianite and green rust-like phases are formed in systems having high aqueous concentrations of phosphate, ferrous iron, and bicarbonate. Goethite and lepidocrocite, characteristic biomineralization products at low ferrous-iron concentrations, are inhibited in the presence of adsorbed phosphate. Thus, deviations in iron (hydr)oxide reactivity with changes in surface composition, such as those noted here for phosphate, need to be considered within natural environments.

\section{Introduction}

Iron (hydr)oxides are ubiquitous in soils and contribute, if not control, the fate and transport of nutrients and contaminants (1). Numerous microorganisms have been identified that induce Fe(III) reduction, the majority of which are dissimilatory iron-reducing bacteria (DIRB) under nonsulfidogenic anaerobic conditions (2-5). Iron (hydr)oxides are reductively dissolved/transformed in anaerobic soils and sediments, releasing $\mathrm{Fe}(\mathrm{II})_{(\mathrm{aq})}$ which may precipitate as ferrous or mixed valent iron containing phases such as magnetite

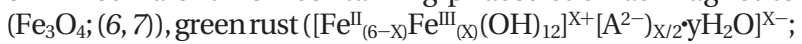
(8)), vivianite $\left(\mathrm{Fe}_{3}\left(\mathrm{PO}_{4}\right)_{2} \cdot n \mathrm{H}_{2} \mathrm{O} ;(9,10)\right)$, or siderite $\left(\mathrm{FeCO}_{3}\right)$ (11). Dissimilatory iron reduction has been extensively studied over the past two decades with various synthetic iron (hydr)oxides serving as the electron acceptor $(7,12-$

* Address correspondence to either author. Phone: (970) 4916235 (T.B.); (650) 723-5238 (S.F.).E-mail: borch@colostate.edu (T.B.); fendorf@stanford.edu (S.F.).

† Stanford University.

‡ Pacific Northwest National Laboratory.

$\S$ Current address: Department of Soil and Crop Sciences, Colorado State University, Fort Collins, Colorado 80523-1170.
17). In addition, the intricate biogenic mineralization pathways have been revealed for iron (hydr) oxides in both batch $(13,17,18)$ and column $(14,19,20)$ systems. However, natural environments often include a complex interaction of numerous organic and inorganic constituents under dynamic flow conditions that may control the reduction of iron (hydr)oxides and the mineralization products.

Many oxyanions (e.g., phosphate and arsenate) interact strongly with iron (hydr)oxides via surface complexation and may, therefore, affect $\mathrm{Fe}(\mathrm{III})$ reducibility, stability, and mineralization pathways $(13,21-25)$. Phosphate, for example, has a profound impact on the reduction and biotransformation of Si-ferrihydrite in the presence of anthraquinone2,6-disulfonate (AQDS) (26). Phosphate increased the extent of iron reduction and promoted the formation of carbonate green rust and vivianite at the expense of magnetite (26). In contrast, phosphate inhibited or had no effect on the reducibility of synthetic and natural iron (hydr)oxides (10), and magnetite was the sole ferrihydrite biomineralization product identified in a PIPES-buffered medium without AQDS (13).

Natural systems experience dynamic flow conditions which will influence chemical-equilibria and may, therefore, control important geochemical processes such as iron biomineralization. For instance, microbial reduction of goethite-coated sand was drastically enhanced in continuousflow column reactors when compared to parallel batch cultures, presumably due to removal of biogenic Fe(II) (27). Additional microbial metabolites, such as bicarbonate, will also accumulate under batch conditions and may dictate the mineralization products formed along with altering microbial respiration rate. The primary factor controlling the nature of the secondary minerals appears to be temporal variation in aqueous $\mathrm{Fe}$ (II) concentration, dictated in large part by the Fe(II) supply rate, which is influenced by many factors such as the concentration of electron donors and other media constituents important for microbial Fe(III) respiration and starting iron (hydr) oxide phase $(14,17,20)$. Nevertheless, most studies have been conducted under batch conditions with abundant electron donor and near-optimal growth conditions (nutrients, temperature, etc.), thus favoring high metabolic activity. Additionally, a systematic examination of variation in surface loading of oxyanions on ferrihydrite reductive transformation remains elusive. Accordingly, here we investigate the impact of surface-associated oxyanions at varying coverages, using phosphate as a model constituent, on the extent of ferrihydrite reduction and resulting biomineralization pathway under static- and dynamic-flow conditions.

\section{Experimental Section}

Preparation of Bacterial Cultures. Shewanella putrefaciens is a facultative, dissimilatory iron reducing bacterium (DIRB) that couples the incomplete oxidization of lactate to acetate with Fe(III) reduction (13). Shewanella putrefaciens strain CN32 was used in this study and maintained in frozen stock cultures containing tryptic soy broth (TSB) amended with $20 \%$ glycerol and stored at $-80^{\circ} \mathrm{C}$. Cells were precultured in TSB (30 g L L ${ }^{-1}$, Difco Laboratories) at $25^{\circ} \mathrm{C}$ and $150 \mathrm{rpm}$ on a horizontal shaker for $12 \mathrm{~h}$, transferred $(1 \mathrm{~mL})$ into fresh TSB $(100 \mathrm{~mL})$ and grown again for $12 \mathrm{~h}$ under aerobic conditions. Cultures were harvested during the late-log phase by centrifugation at $4500 \mathrm{~g}$ for $10 \mathrm{~min}$ at $5{ }^{\circ} \mathrm{C}$, washed once in $100 \mathrm{~mL}$ of anaerobic $10 \mathrm{mM}$ PIPES (piperazine-1,4bis(2-ethanesulfonic acid) buffered synthetic groundwater medium (SGM; pH 7.2), and resuspended in groundwater 
medium to obtain the desired cell concentration. Cell culture densities were determined using standard DAPI staining procedures and a Nikon epifluorescent microscope. A $1 \mathrm{~g}$ sample of Fe-coated sand was added to $9 \mathrm{~mL}$ of $10 \mathrm{mM}$ sodium pyrophosphate and subjected to sonication before DAPI staining. Standard procedures for culturing anaerobic bacteria and preparation of anoxic systems were used throughout. All experiments were conducted in an anaerobic glovebag (Coy Laboratories, Inc., Grass Lake, MI) containing an anoxic gas mixture $\left(\mathrm{N}_{2} 95 \% ; \mathrm{H}_{2} 5 \%\right)$.

Synthetic Groundwater Medium. Synthetic groundwater medium (SGM) of the following composition was used in all experiments (in mg L${ }^{-1}$ ): $\mathrm{KCl}$ (5), $\mathrm{MgSO}_{4}$ (50), $\mathrm{NaCl}$ (30), $\mathrm{NH}_{4} \mathrm{Cl}$ (0.95), $\mathrm{KH}_{2} \mathrm{PO}_{4}$ (0.95; batch systems only), PIPES (3020), $0.1 \mathrm{~mL}$ Wolfe's mineral solution (28), and finally, $\mathrm{pH}$ adjusted to 7.2 by addition of $\mathrm{NaOH}$. Sodium lactate $(3 \mathrm{mM})$ was added as the electron donor. Media and buffers were made anoxic by boiling and purging with $\left(\mathrm{O}_{2}\right.$-free $) \mathrm{N}_{2}$ gas .

Ferrihydrite Coated Sand and Phosphate Sorption. Ferrihydrite was prepared by rapid titration ( $<10 \mathrm{~min})$ of a $\mathrm{FeCl}_{3}$ suspension with $\mathrm{NaOH}(0.4 \mathrm{M})$ to a pH of 7.5 (29) and coated on quartz sand as described in detail previously (14, 20). The concentration of Fe on the sand was $6-8 \mathrm{~g} \mathrm{Kg}^{-1}$. The presence and purity of 2-line ferrihydrite was verified using $\mathrm{X}$-ray diffraction (XRD) and X-ray absorption spectroscopy (XAS). Specific surface area of the Fe-coated sand was $2.6 \mathrm{~m}^{2}$ $\mathrm{g}^{-1}$ (uncoated quartz sand was $0.16 \mathrm{~m}^{2} \mathrm{~g}^{-1}$ based on $\mathrm{Kr}$ BET)) as determined by $\mathrm{N}_{2} / \mathrm{Kr}$-BET analysis using a BeckmanCoulter SA3100 analyzer. Ferrihydrite was reacted with $\mathrm{PO}_{4}{ }^{3-}$ (as $\mathrm{Na}_{2} \mathrm{HPO}_{4}$ ) at concentrations from 10 to $2000 \mu \mathrm{M}$ in synthetic groundwater medium for 3 days. Phosphate adsorption was well described by the Langmuir equation, and the monolayer sorption $(\Gamma)$ was $0.28 \mathrm{~g} \mathrm{P} \mathrm{Kg}^{-1}$ solids (or 797 mmole $\mathrm{P} \mathrm{Kg}^{-1}$ ferrihydrite).

Role of Sorbed P on Fe-Mineralization. Reactions were performed in $125 \mathrm{~mL}$ serum bottles containing $100 \mathrm{~mL}$ of sterile (autoclaved at $121^{\circ} \mathrm{C}$ for $15 \mathrm{~min}$ ) synthetic groundwater medium and $1 \mathrm{~g}$ of ferrihydrite-coated sand. Phosphate was coated to various degrees (50 and $100 \%$ of the adsorption maximum, $\Gamma_{\max }$ ) on the ferrihydrite-coated sand; excess $\mathrm{P}$ was removed by replacing the aqueous solution with fresh synthetic groundwater medium. The role of phosphate on secondary mineralization was investigated by inoculation with S. putrefaciens to a cell density of $\sim 10^{8} \mathrm{~mL}^{-1}$ (biotic) or by reacting 0.2 or $2 \mathrm{mM}$ ferrous sulfate (abiotic) with the (P-)Fe-coated sand for $7 \mathrm{~d}$. Triplicate samples were placed on a horizontal shaker at $80 \mathrm{rpm}$ at $25{ }^{\circ} \mathrm{C}$ and sampled periodically for $\mathrm{Fe}(\mathrm{II})$ and $\mathrm{pH}$ with a sterile syringe.

Flow experiments were conducted in columns $(3.8 \mathrm{~cm}$ diameter (ID)) with 4 sampling ports located at 1.7, 5, 8.3, and $11.7 \mathrm{~cm}$ along the flow-path, as described previously (20). Ferrihydrite-coated sand was coated with phosphate to $\Gamma_{\max }$, washed once in synthetic groundwater medium, and then inoculated with S. putrefaciens to a cell density of $\sim 8$ $\times 10^{8} \mathrm{~g}^{-1}$. Columns were packed and prepared as described previously (20); the flow rate was maintained at $373 \mathrm{~mL} \mathrm{~d}^{-1}$ (2.9 pore volumes) upward through the column.

Analytical Procedures. Major solutes and $\mathrm{pH}$ were measured as a function of time. Upon termination of the column experiments, the solids were carefully extracted and homogenized at $3.1 \mathrm{~cm}$ intervals, rinsed in $10 \mathrm{~mL}$ anoxic DI water, and dried in the glovebag. Ferrous iron was determined spectrophotometrically using the Ferrozine method (30). Aqueous and solid phase (after digestion in $6 \mathrm{M}$ trace metal grade $\mathrm{HCl}$ for $24 \mathrm{~h}$ ) concentrations of $\mathrm{P}$ and $\mathrm{Fe}$ were determined using inductively coupled plasma optical emission spectroscopy (ICP-OES). Acetate and lactate concentrations were determined by ion chromatography (IC). Samples for X-ray absorption spectroscopic analyses were sonicated $(<4 \mathrm{~h})$ to remove the Fe from the sand, vacuum filtered onto a cellulose acetate filter to form a homogenously distributed Fe layer, dried ( $\sim 30 \mathrm{~min})$, and then sealed between two pieces of Kapton polyimide film to prevent oxidation while minimizing X-ray absorption. The structural environment of Fe was determined using X-ray diffraction (XRD) and extended $\mathrm{X}$-ray absorption fine structure (EXAFS) spectroscopy at the Stanford Synchrotron Radiation Laboratory (SSRL) on beamlines 2-3 (bend magnet), 11-2 (26-pole wiggler), and 11-3 (XRD), running under dedicated conditions. The XAS analytical procedure used here were similar to those described previously (20). Energy selection was accomplished with a Si (220) monochromator, and spectra were recorded by fluorescent X-ray production using a Lytle-detector. A set of Fe reference compounds was used to perform linear combination $k^{3}$-weightened EXAFS spectral fitting using the SIXPACK interface to IFEFIT (31). Linear combinations of the reference compounds were optimized and the only variable parameters were the fractions of each reference compounds. Reference compounds were chosen based on their likelihood of being a reaction product (including, for example, criteria such as elemental composition), and were included in the fit only if they contributed with a fraction of 0.05 or more. Mass balance in Fe(II)/Fe(III) and Mössbauer spectroscopy were used to constrain the LC-EXAFS fitting. Detection limit for minor constituents is approximately $5 \%$, as described previously (20).

Mössbauer spectroscopy, with a detection limit of approximately 2 wt. \%, was used to confirm the EXAFS analysis. Mössbauer spectra of the initial and bioreduced P-ferrihydrite were obtained at $303,77,40$, and $12 \mathrm{~K}$ to elucidate the nature of the residual ferrihydrite and mineralization products. The Fe-coated quartz grains were sonicated 10 min with deoxygenated water to strip Fe-oxide from the sand particles. Sonication, filtration, washing, drying, and packing were performed in an anoxic chamber. A closed-cycle cryostat (ARS, Allentown) was employed for low temperature measurements. The Mössbauer data were modeled with the Recoil software (University of Ottawa, Canada) using a Voigt-based spectral fitting routine ((32) as described in detail elsewhere (26)).

\section{Results}

Impact of Phosphate on Ferrihydrite Reduction and Mineralization: Static-Flow Systems. The role of varying phosphate coverage under biotic and abiotic conditions was investigated in batch systems to advance our understanding of how strongly sorbing oxyanions impact biomineralization of ferrihydrite. Decreasing production of ferrous iron is observed with increasing phosphate coverage during reduction of ferrihydrite by $S$. putrefaciens (Figure la). Microbial oxidation of lactate to acetate, and concurrent reduction of $\mathrm{Fe}(\mathrm{III})$ to $\mathrm{Fe}(\mathrm{II})$, is correlated with the extent of phosphatecoverage (Figure 1a). Microbially induced ferrihydrite degradation is ca. linearly correlated with phosphate coverage $\left(R^{2}=0.998\right)$, and a more than 3 -fold decrease in the extent of transformation is observed at $\Gamma_{\max }$ (Figure 1b). The impact of surface-associated phosphate on the nature of secondary minerals is also considerable. Magnetite, green rust, and goethite are the dominant secondary Fe phases in the absence of phosphate (Figure 1c). When ferrihydrite is loaded with phosphate at $50 \%$ of $\Gamma_{\max }$, only magnetite and green rust are observed, while small amounts of green rust are the sole secondary Fe phase at $100 \%$ coverage. Goethite formation is inhibited in the presence of phosphate.

The role of microbial activity and phosphate in the secondary mineralization of ferrihydrite was further evaluated by (abiotically) reacting $\mathrm{Fe}(\mathrm{II})\left(0.2 \mathrm{mM}\right.$ or $\left.2.0 \mathrm{mM} \mathrm{FeSO}_{4}\right)$ with ferrihydrite coated sand (Table S1 in Supporting Information). In the absence of phosphate, reaction of ferrous sulfate with ferrihydrite yields lepidocrocite as the primary 

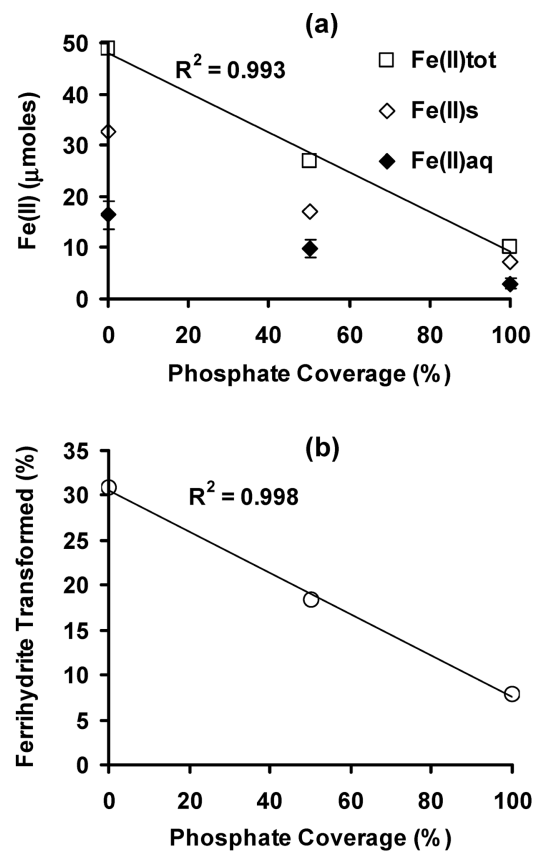

(c)

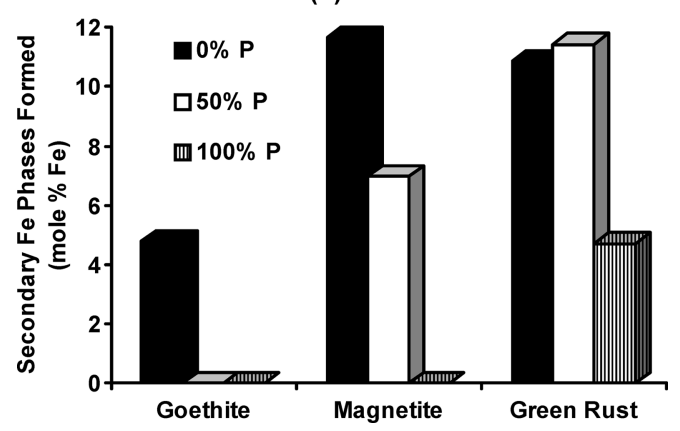

FIGURE 1. Ferrous iron production (a), ferrihydrite transformation (b), and resulting secondary Fe phases formed (c) in a batch system with ferrihydrite-coated sand and dissimilatory iron reducing bacteria (Shewanella putrefaciens, strain CN32) as a function of phosphate coverage after $7 \mathrm{~d}$ of reaction. Aqueous data are the average of triplicate measurements and error bars represent one standard deviation.

product at low concentration $\left(0.2 \mathrm{mM} \mathrm{FeSO}_{4}\right)$, with small quantities of goethite and magnetite, while higher concentration yields goethite and magnetite as the dominant products $\left(2.0 \mathrm{mM} \mathrm{FeSO}_{4}\right)$. By contrast, goethite is not formed in the presence of surface associated phosphate $(50 \%$ and $100 \%$ P coverage) and the proportion of all products are greatly diminished (Table S1 in the Supporting Information). Additionally, green rust and vivianite are observed in experiments containing phosphate.

Impact of Phosphate on Ferrihydrite Mineralization: Dynamic-Flow Systems. Dynamic flow provides a continuous supply of electron donor and limits accumulation of microbial metabolites, thus potentially altering the reaction pathways and providing conditions more reflective of natural environments. The impact of surface-associated phosphate on biomineralization of ferrihydrite was, therefore, investigated in column studies under advective flow conditions. Lactate concentrations decrease from $3.1 \mathrm{mM}$ in the effluent to nearly $0.5 \mathrm{mM}$ by day 2 but then increase to $2.85 \mathrm{mM}$ at day 4 where it remains for the duration of the experiment (Figure 2). The concentration profile for acetate mirrors that of lactate, but is contrasted by the $\mathrm{Fe}(\mathrm{II})_{\mathrm{aq}}$ concentration which steadily increases throughout the experiment, reaching a maximum concentration of $0.25 \mathrm{mM}$ after $17 \mathrm{~d}$. A stop-

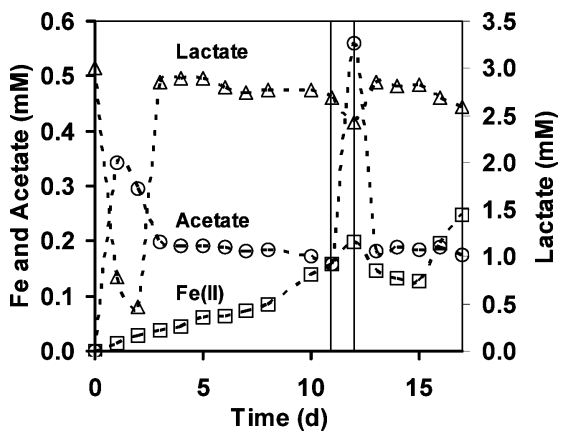

FIGURE 2. Effluent concentrations of Fe, acetate, and lactate from column experiments with phosphate-coated ferrihydrite. The vertical lines indicate the onset of a stop flow event.

flow event at $11 \mathrm{~d}$ illustrates the disequilibrium as noted by the 3 -fold increase in acetate concentration.

The concentration of acetate and Fe(II) aq both increase along the flow-path. However, the temporal trends in acetate and $\mathrm{Fe}(\mathrm{II})_{\mathrm{aq}}$ gradients are inversely correlated (Figure 3); acetate concentrations decrease while Fe(II) concentrations increase with reaction time. The concentration of Fe-total in the solid phase is slightly higher downstream in the column (Figure $3 \mathrm{c})$, and only a minor fraction $(\sim 3 \%$ or $\sim 0.6 \mathrm{mmol}$ $\mathrm{Fe}$ ) is eluting from the column during the $17 \mathrm{~d}$ of reaction. Ferrous iron concentration in the solid phase increases within the first $8 \mathrm{~cm}$ of the column and then decreases at $12 \mathrm{~cm}$ (Figure $3 \mathrm{~d}$ ). Mass balance between lactate oxidation (1.3 mmol lactate oxidized) and Fe(III) reduction (5.2 $\mathrm{mmol} \mathrm{Fe}-$ (III) reduced) is obtained, verifying that Fe(III) was the sole electron acceptor used in the respiration process. The number of bacterial cells in the column was additionally quite consistent throughout the column after $17 \mathrm{~d}$ of reaction, and less than 1 order of magnitude of cells eluted from the column during the experiment (Figure 3e).

Ferrihydrite is primarily converted to magnetite throughout the column (Figure $4 a-b$ ) as revealed by EXAFS spectroscopy (Figure 4a) and confirmed by XRD (data not shown) and Mössbauer spectroscopy (Figure 5). However, linear combination fits of the EXAFS spectra also indicate a gradual increase in vivianite- and green rust-like phases downstream in the column, with the highest concentration observed $8.3 \mathrm{~cm}$ from the inlet (Figure $4 \mathrm{~b}$ ). The amount of $\mathrm{Fe}(\mathrm{II})$ estimated using linear combination fit of the solidphase products throughout the column correlates well with the Fe(II) concentration measured by the Ferrozine method and Mössbauer spectroscopy (Figures 4c and 5).

Mössbauer spectra were obtained at various temperatures from the initial phosphate-coated ferrihydrite as well as 8 and $12 \mathrm{~cm}$ from the column inlet after $17 \mathrm{~d}$ of reaction (Figure 5 and Figure S1 in the Supporting Information). The Mössbauer spectra were in general agreement with the EXAFS data and chemical extractions, and thus we focus solely on a description of the analysis of the sample obtained $8-\mathrm{cm}$ from the column inlet. The $303 \mathrm{~K}$ spectrum of the $8 \mathrm{~cm}$ sample (Figure 5a) displayed features exemplifying the magnetite sextets (two sextet features), a broad doublet due to paramagnetic Fe(II) phases (e.g., vivianite, green rust, etc.), and a narrow central doublet mainly due to residual ferrihydrite. Spectra at lower temperatures (77-K, 40-K, and $12-\mathrm{K})$ were mainly collected to see whether green rust and vivianite phases, if present, can be resolved from residual ferrihydrite and magnetite features. The Fe(II) doublet feature in the 77-K spectrum remains broad, implying the presence of more than one Fe(II) phase (Figure 5b), and it was apparent that siderite is absent (33)). 

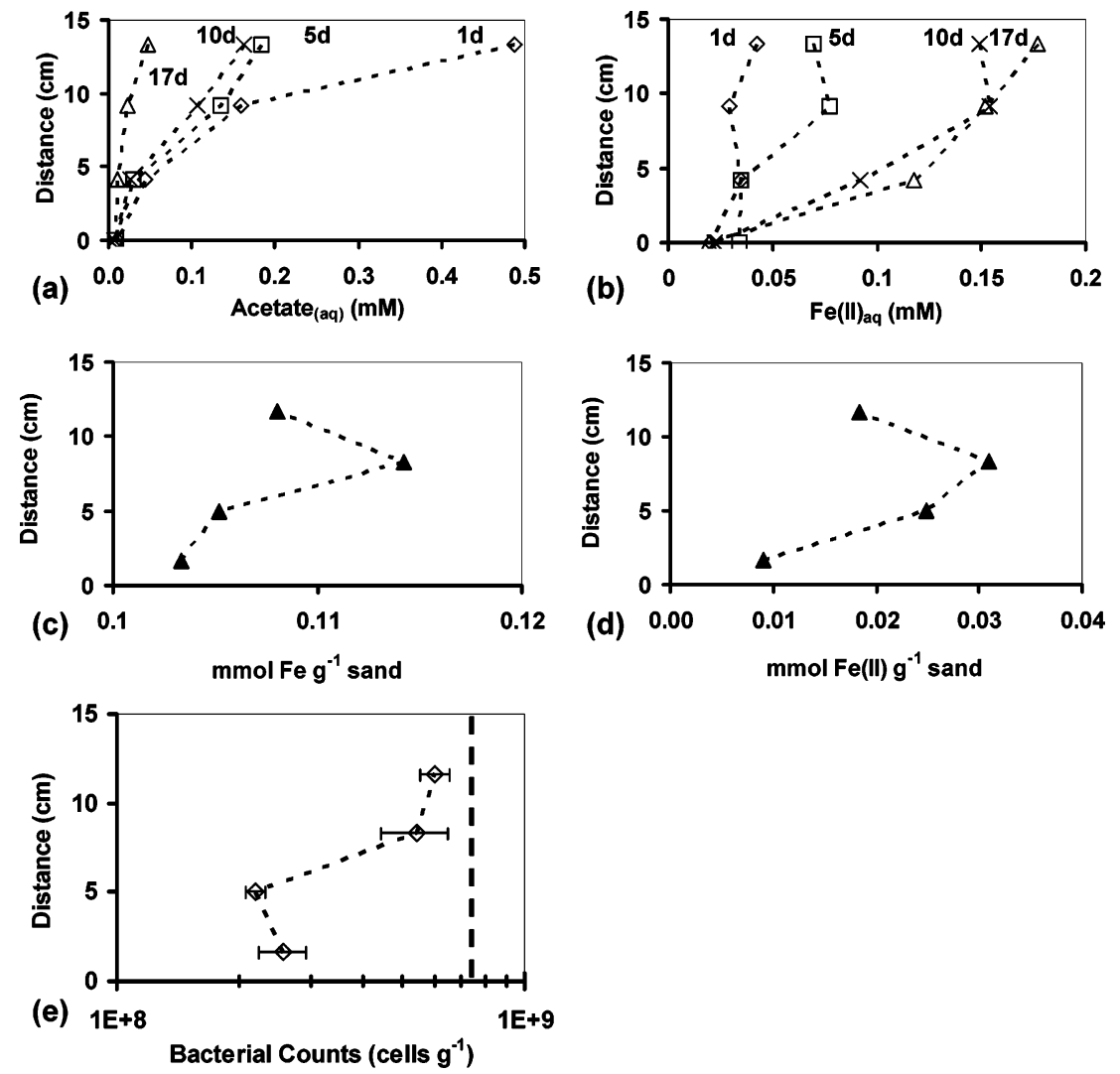

FIGURE 3. Spatial and temporal distribution of acetate (a) and aqueous $\mathrm{Fe}(\mathrm{II})_{\text {aq }}$ (b) along column length. Concentration of solid-phase $\mathrm{Fe}_{\text {total }}$ (c), solid-phase Fe(II) (d), and bacterial cell distribution (e) within the column at day 17 (bracket line represents bacterial counts at day 1).

\section{Discussion}

The inverse correlation between ferrous iron production and surface-associated phosphate illustrates how strongly sorbing oxyanions stabilize the structure of short-range order iron hydroxides, such as ferrihydrite, toward dissimilatory Fe reduction and secondary mineral transformation. Surfaceassociated phosphate inhibits transformation of iron (hydr)oxides due, in part, to an increase in the free energy of activation $(23,25,34,35)$. Previous studies, however, observed that phosphate had only a minor impact on bacterial reduction of natural iron (hydr) oxides (10), and that addition of phosphate to the aqueous phase stimulated reduction of synthetic Si-ferrihydrite in the presence of AQDS (26). Phosphate, in contrast, was noted to inhibit reduction and mineralization of Ni-ferrihydrite (36). In $80 \mathrm{~d}$ batch experiments of $S$. putrefaciens and ferrihydrite (20 mM lactate), high concentrations of phosphate $(4.0 \mathrm{mM}$ initial concentration) increased Fe(II) (aq) concentrations relative to systems with low phosphate $(0.4 \mathrm{mM}$ initial concentrations)-albeit that viable cell numbers were approximately equal between the two systems after the $80 \mathrm{~d}$ reaction period (18). Similar length (75 d) studies of ferrihydrite reduction in the presence of $30 \mathrm{mM}$ lactate were conducted in carbonate and PIPES buffered systems with and without addition of $4 \mathrm{mM} \mathrm{P}$ (aqueous $P$ concentration were near analytical detection after $4 \mathrm{~d}$ reaction period) and indicate that $\mathrm{P}$ did not significantly influence the amount of $3 \mathrm{M} \mathrm{HCl}$ extractable Fe(II) (13). Nevertheless, $P$ consistently resulted in overall higher lactate oxidation compared to solutions where $\mathrm{P}$ was absent in shorter-term (20 d) experiments (13). The extent of iron reduction in our experiments is, however, similar to others with synthetic ferrihydrite (10), showing that only $13 \%$ was bioreduced in the presence of $4 \mathrm{mM}$ phosphate after $39 \mathrm{~d}$ of reaction with $S$. putrefaciens. The somewhat contrasting findings of various studies, including this one, may be explained by the differences in the media of the different studies, cell preparation, ferrihydrite nature (aggregates vs surface coated sand), and mode of phosphate addition (aqueous vs sorbed to ferrihydrite before incubation). Here, we used lactate concentrations 7-10 times less than the previous studies and phosphate concentrations below the oxide's sorption capacity; additionally, differences in buffer type and concentration prevailed in these studies $(10,26)$. Iron bioreduction can differ in bicarbonate compared to PIPES buffer $(13,37)$, low versus high electron donor to acceptor ratio (38), and in the presence of readily available phosphate as described above (18).

In addition to the extent of ferrihydrite reduction being modified, the transformation pathway is also vastly different in the presence of phosphate. A 4-fold decrease in the extent of ferrihydrite transformation is observed in the presence of phosphate at maximum surface coverage, correlating well with the corresponding decrease in $\mathrm{Fe}$ (II) production (Figure 1). The most notable difference in the secondary iron phases is the apparent inhibition of goethite (Figure 1c). Magnetite and green rust formation, albeit not the proportion, is in concurrence with previous studies performed in a minimal growth medium (18) but differs from the secondary phases formed (i.e., vivianite and siderite) under condition where the growth medium is optimized to achieve more rapid rates of reduction (13).

Lepidocrocite is the dominant secondary phase in the absence of phosphate at low ferrous iron concentrations $(0.2$ $\mathrm{mM} \mathrm{FeSO}_{4}$ ) in abiotic reactions, while goethite and magnetite are formed in equal amounts at high concentrations of ferrous iron (2.0 mM), in agreement with previous studies (37). In contrast to the extent of ferrihydrite mineralization (44 and $59 \%$ transformed) observed in the absence of phosphate, only $10-20 \%$ of the ferrihydrite is mineralized in the presence of phosphate (Table S1 in the Supporting Information). This 

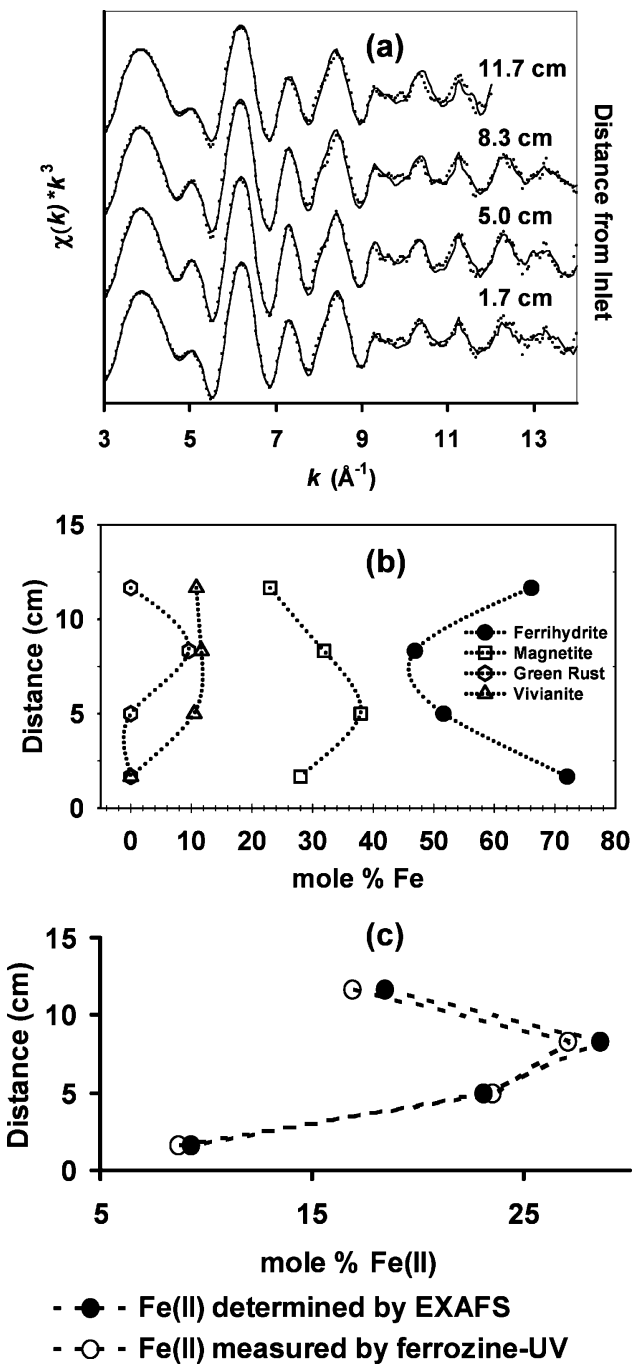

FIGURE 4. (a) $\boldsymbol{k}^{3}$-weighted EXAFS spectra (solid line) and linearcombination fit (dotted line) for the solid-phase products throughout the column. (b) Corresponding percents of Fe phases (mol-basis) resulting from linear combination fits (data are $\pm 5 \%$ and the detection limit is $5 \mathrm{~mol} \% \mathrm{Fe}$ ). (c) Comparison of the Fe(II) proportion determined by EXAFS fitting and ferrozine assay.

result supports the premise that phosphate stabilizes the structure of ferrihydrite by inhibiting reduction, poisons the formation of goethite, and promotes the formation of green rust and vivianite-the latter forms only at high ferrous iron and phosphate concentrations. The formation of carbonate green rust under biotic conditions in the absence of phosphate is likely a result of the microbial respiration which results in the formation and accumulation of bicarbonate under batch conditions. While batch systems can be used to constrain important biomineralization processes, chemicalequilibria at bacteria-oxide interfaces will be impacted by dynamic flow in a large proportion of natural media (e.g., nutrient supply and metabolite removal). Thus, the remainder of this discussion will primarily focus on Fe biomineralization processes observed under advective flow conditions.

The oxidation pattern of lactate to acetate is similar to previous studies in the absence of phosphate, although the overall respiration on unamended ferrihydrite is decreased by more than half within the first $8 \mathrm{~d}$ of reaction (20) relative to that with adsorbed phosphate. The steep decline in microbial respiration (i.e., acetate production) observed in the absence of phosphate is probably a result of rapid formation of highly crystalline iron phases $(14,20)$. Temporal variation in $\mathrm{Fe}(\mathrm{II})_{\mathrm{aq}}$ concentration also differ between systems

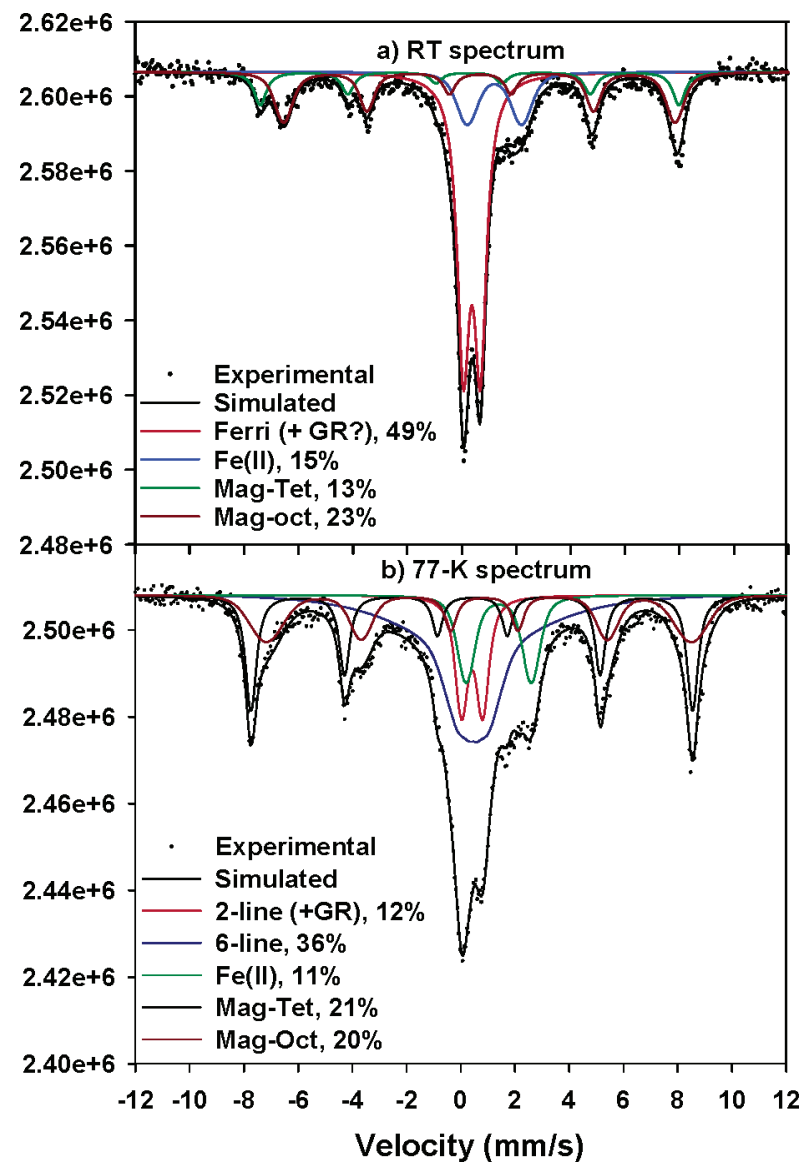

FIGURE 5. Mössbauer spectra of biomineralization products $8.3 \mathrm{~cm}$ from the column inlet obtained at $303-\mathrm{K}(\mathrm{a})$ and $77-\mathrm{K}(\mathrm{b})$. The simulated fit (solid lines) to the experimental spectra (dotted) are shown for the column reacted for $\mathbf{1 7} \mathrm{d}$. Abbreviation: Ferrihydrite (Ferri), magnetite (Mag), and green rust (Gr).

with and without phosphate. With phosphate present $(100 \%$ $\left.\Gamma_{\max }\right), \mathrm{Fe}(\mathrm{II})$ gradually increases with time while in the absence of phosphate high aqueous Fe(II) concentrations form initially ( $t<5 \mathrm{~d}$ ) followed by a gradual decrease with time (Figures 2 and 3 and ref 20).

The dominant mineralization product formed during dissimilatory iron reduction of phosphate-amended ferrihydrite under advective flow is magnetite (Figures 4 and 5), consistent with earlier reports of mineralization products in the absence of phosphate (20), with only a minor formation of vivianite- and or green rust-like phases downstream in the column (Figure 4b). Ferrihydrite remains, however, the major solid phase after $17 \mathrm{~d}$ of reaction. In contrast to the considerable formation of goethite observed in both column studies (see ref 20) and (a)biotic batch studies (Figure 1c and Table S1 in the Supporting Information) in the absence of phosphate, goethite was not formed in the presence of phosphate. Abiotic investigations indicate that phosphate inhibits goethite formation by hindering the dissolution of ferrihydrite rather than by interfering with nucleation and growth of goethite $(25,34,39)$.

Mössbauer spectroscopy provides evidence of a broad $\mathrm{Fe}(\mathrm{II})$ doublet feature (Figure 5a), indicative of multiple ferrous bearing phases inclusive of vivianite, green rust, and siderite (although the latter could be excluded due to the absence of an asymmetric sextet at 12-K (33)). The Mössbauer fit-derived $\mathrm{Fe}$ (II) content is similar to that determined by the Ferrozine assay and supports the EXAFS fitting (Figure 4c). While it is well-established that the extent of iron (hydr)oxide reduction will increase under flow-conditions (27), this study further indicates that the resulting secondary Fe 
minerals will differ from closed-systems especially when high microbial metabolism is favored.

Previous thermodynamic considerations suggested that aqueous complexants, or ligands such as phosphate and bicarbonate, could enhance bacterial iron (hydr)oxide reduction by drawing Fe(II) from the oxide surface $(40,41)$. The initial aqueous phosphate concentration in this batch study ( $\leq 25 \mu \mathrm{M}$ for $100 \% \Gamma_{\max }$ ) was $16-143$ times lower than in studies showing increased iron reduction or vivianite formation $(13,41)$ and may be insufficient to thermodynamically favor iron reduction. Thus, the potential impact of phosphate, or other ligands, on iron reduction needs to be placed within the context of the aqueous to solid-phase ratio.

Bioreduction and mineralization pathways of iron (hydr)oxides are influenced by strongly sorbing oxyanions such as phosphate. Our studies illustrate slow respiration on a presumably "bioavailable" form of Fe(III), even when supplied with an electron donor (lactate) concentration of $3 \mathrm{mM}$; "leaner" conditions common to most natural environments would likely exaggerate the limited reduction of phosphated ferrihydrite. Decreased iron availability to plants in phosphate amended soils (42) and increased proportions of short-range order iron (hydr)oxides observed in phosphatic soils (43) may further be explained by the proportional reduction noted here. Additionally, the absence of goethite and typical lower fraction of crystalline Fe phases in phosphatic soils results from a stabilization of ferrihydrite. Thus, when considering the reactivity of iron phases such as ferrihydrite, it is important to appreciate modifications induced by surface composition such as that noted here for phosphate.

\section{Acknowledgments}

Mössbauer analysis was performed in the Environmental Molecular Sciences Laboratory, a national scientific user facility sponsored by the Department of Energy's Office of Biological and Environmental Research, located at Pacific Northwest National Laboratory. We thank G. Li, C. Hansel, M. Ginder-Vogel, B. Stewart, B. Kocar, and D. Richter for their invaluable help on this project. This research was supported by the U.S. Department of Energy's ERSD program (grant no. ER63609-1021814). Portions of this research were carried out at the Stanford Synchrotron Radiation Laboratory, a national user facility operated by Stanford University on behalf of the U.S. Department of Energy, Office of Basic Energy Sciences.

\section{Supporting Information Available}

Fe(II)-induced (abiotic) conversion of ferrihydrite as a function of $\mathrm{Fe}(\mathrm{II})\left(\mathrm{FeSO}_{4}\right)$ concentration and phosphate coverage following $7 \mathrm{~d}$ of reaction (TABLE S1) and Mössbauer spectra of the initial phosphate-coated ferrihydrite (FIGURE S1). This material is available free of charge via the Internet at http://pubs.acs.org.

\section{Literature Cited}

(1) Huang, P. M.; Wang, M. K. Formation chemistry and selected surface properties of iron oxides. Adv. GeoEcol. 1997, 30, 241270.

(2) Borch, T.; Inskeep, W. P.; Harwood, J. A.; Gerlach, R. Impact of ferrihydrite and anthraquinone-2,6-disulfonate on the reductive transformation of 2,4,6-trinitrotoluene by a gram-positive fermenting bacterium. Environ. Sci. Technol. 2005, 39, 71267133.

(3) Lovley, D. R. Fe(III) and Mn(IV) Reduction. In Environmental Microbe-Metal Interactions; Lovley, D. R., Ed.; ASM Press: Washington, DC, 2000; pp 3-30.

(4) Lovley, D. R.; Phillips, E. J. P. Organic matter mineralisation with reduction of ferric iron in anaerobic sediments. Appl. Environ. Microbiol. 1986, 51, 683-689.
(5) Afonso, M. D.; Stumm, W. Reductive dissolution of iron(III) (hydr)oxides by hydrogen-sulfide. Langmuir 1992, 8, 16711675 .

(6) Heron, G.; Christensen, T. H.; Tjell, J. C. Oxidation capacity of aquifer sediments. Environ. Sci. Technol. 1994, 28, 153-158.

(7) Lovley, D. R.; Stolz, J. F.; Nord, G. L. J.; Phillips, E. J. P. Anaerobic production of magnetite by a dissimilatory iron-reducing microorganism. Nature 1987, 330, 252-254.

(8) Trolard, F.; Genin, J.-M. R.; Abdelmoula, M.; Bourrie, G.; Humbert, B.; Herbillon, A. Identification of a green rust mineral in a reductomorphic soil by Mossbauer and Raman spectroscopies. Geochim. Cosmochim. Acta 1997, 61, 1107-1111.

(9) Peretyazhko, T.; Sposito, G. Iron(III) reduction and phosphorous solubilization in humid tropical forest soils. Geochim. Cosmochim. Acta 2005, 69, 3643-3652.

(10) Zachara, J. M.; Fredrickson, J. K.; Li, S. M.; Kennedy, D. W.; Smith, S. C.; Gassman, P. L. Bacterial reduction of crystalline Fe3+ oxides in single phase suspensions and subsurface materials. Am. Mineral. 1998, 83, 1426-1443.

(11) Coleman, M. L.; Hedrick, D. B.; Lovley, D. R.; White, D. C.; Pye, $\mathrm{K}$. Reduction of $\mathrm{Fe}(\mathrm{III})$ in sediments by sulphate-reducing bacteria. 1993, 361, 436-438.

(12) Burgos, W. D.; Fang, Y.; Royer, R. A.; Yeh, G. T.; Stone, J. J.; Jeon, B. H.; Dempsey, B. A. Reaction-based modeling of quinonemediated bacterial iron(III) reduction. Geochim. Cosmochim. Acta 2003, 67, 2735-2748.

(13) Fredrickson, J. K.; Zachara, J. M.; Kennedy, D. W.; Dong, H.; Onstott, T. C.; Hinman, N. W.; Li, S.-M. Biogenic iron mineralization accompanying the dissimilatory reduction of hydrous ferric oxide by a groundwater bacterium. Geochim. Cosmochim. Acta 1998, 62, 3239-3257.

(14) Hansel, C. M.; Benner, S. G.; Nico, P.; Fendorf, S. Structura constraints of ferric (hydr) oxides on dissimilatory iron reduction and the fate of Fe(II). Geochim. Cosmochim. Acta 2004, 68, 32173229.

(15) Liu, C. X.; Kota, S.; Zachara, J. M.; Fredrickson, J. K.; Brinkman, C. K. Kinetic analysis of the bacterial reduction of goethite. Environ. Sci. Technol. 2001, 35, 2482-2490.

(16) Roden, E. E.; Zachara, J. M. Microbial reduction of crystalline iron(III) oxides: Influence of oxide surface area and potentia for cell growth. Environ. Sci. Technol. 1996, 30, 1618-1628.

(17) Zachara, J. M.; Kukkadapu, R. K.; Fredrickson, J. K.; Gorby, Y. A.; Smith, S. C. Biomineralization of poorly crystalline Fe(III) oxides by dissimilatory metal reducing bacteria (DMRB). Geomicrobiol. J. 2002, 19, 179-207.

(18) Glasauer, S.; Weidler, P. G.; Langley, S.; Beveridge, T. J. Controls on $\mathrm{Fe}$ reduction and mineral formation by a subsurface bacterium. Geochim. Cosmochim. Acta 2003, 67, 1277-1288.

(19) Benner, S. G.; Hansel, C. M.; Wielinga, B. W.; Barber, T. M.; Fendorf, S. Reductive dissolution and biomineralization of iron hydroxide under dynamic flow conditions. Environ. Sci. Technol. 2002, 36, 1705-1711.

(20) Hansel, C. M.; Benner, S. G.; Neiss, J.; Dohnalkova, A.; Kukkadapu, R. K.; Fendorf, S. Secondary mineralization pathways induced by dissimilatory iron reduction of ferrihydrite under advective flow. Geochim. Cosmochim. Acta 2003, 67, 2977-2992.

(21) Wilson, G. V.; Rhoton, F. E.; Selim, H. M. Modeling the impact of ferrihydrite on adsorption-desorption of soil phosphorus. Soil Sci. 2004, 169, 271-281.

(22) Dixit, S.; Hering, J. G. Comparison of $\operatorname{arsenic}(\mathrm{V})$ and $\operatorname{arsenic}(\mathrm{III})$ sorption onto iron oxide minerals: Implications for arsenic mobility. Environ. Sci. Technol. 2003, 37, 4182-4189.

(23) Shaw, S. P.; S. E.; Bryan, N. D.; Livens, F. R. The kinetics and mechanisms of goethite and hematite crystallization under alkaline conditions, and in the presence of phosphate. Am. Mineral. 2005, 90, 1852-1860.

(24) Arai, Y.; Sparks, D. L. ATR-FTIR spectroscopic investigation on phosphate adsorption mechanisms at the ferrihydrite-water interface. J. Colloid Interface Sci. 2001, 241, 317-326.

(25) Galvez, N.; Barron, V.; Torrent, J. Effect of phosphate on the crystallization of hematite, goethite, and lepidocrocite from ferrihydrite. Clays Clay Miner. 1999, 47, 304-311.

(26) Kukkadapu, R. K.; Zachara, J. M.; Fredrickson, J. K.; Kennedy, D. W. Biotransformation of two-line silica-ferrihydrite by a dissimilatory Fe(III)-reducing bacterium: formation of carbonate green rust in the presence of phosphate. Geochim. Cosmochim. Acta 2004, 68, 2799-2814.

(27) Roden, E. E.; Urrutia, M. M.; Mann, C. J. Bacterial reductive dissolution of crystalline Fe(III) oxide in continuous-flow column reactors. Appl. Environ. Microbiol. 2000, 66, 1062-1065. 
(28) Balch, W. E.; Fox, G. E.; Magrum, L. J.; Woese, C. R.; Wolfe, R. $\mathrm{S}$. Methanogens reevaluation of a unique biological group. Microbiol. Rev. 1979, 43, 260-296.

(29) Cornell, R. M.; Schwertmann, U. The Iron Oxides: Structure, Properties, Reactions, Occurrence and Uses, 2nd ed.; VCH: Weinheim, Germany, 2003.

(30) Stookey, L. Ferrozine-a new spectrophotometric reagent for iron. Anal. Chem. 1970, 42, 779-781.

(31) Webb, S.; SixPACK, V. 0.52; Stanford Synchrotron Radiation Laboratory: Menlo Park, CA, 2002.

(32) Rancourt, D. G.; Ping, J. Y. Voigt-based methods for arbitraryshape static hyperfine parameter distributions in mossbauerSpectroscopy. Nucl. Instrum. Methods Phys. Res. Sect. B 1991, 58, 85-97.

(33) Wade, M. L.; Agresti, D. G.; Wdowiak, T. J.; Armendarez, L. P.; Farmer, J. D. A Mossbauer investigation of iron-rich terrestrial hydrothermal vent systems: Lessons for Mars exploration. J. Geophys. Res., [Planets] 1999, 104, 8489-8507.

(34) Paige, C. R.; Snodgrass, W. J.; Nicholson, R. V.; Scharer, J. M.; $\mathrm{He}, \mathrm{Q}$. H. Effect of phosphate on the transformation of ferrihydrite into crystalline products in alkaline media. Water, Air, Soil Pollut. 1997, 97, 397-412.

(35) Willett, I. R. The reductive dissolution of phosphated ferrihydrite and strengite. Aus. J. Soil Res. 1985, 23, 237-244.

(36) Fredrickson, J. K.; Zachara, J. M.; Kukkadapu, R. K.; Gorby, Y. A.; Smith, S. C.; Brown, C. F. Biotransformation of Ni-substituted hydrous ferric oxide by an Fe(III)-reducing bacterium. Environ. Sci. Technol. 2001, 35, 703-712.

(37) Hansel, C. M.; Benner, S. G.; Fendorf, S. Competing Fe(II)Induced Mineralization Pathways of Ferrihydrite. Environ. Sci. Technol. 2005, 39, 7147-7153.
(38) Fredrickson, J. K.; Kota, S.; Kukkadapu, R. K.; Liu, C. X.; Zachara, J. M. Influence of electron donor/acceptor concentrations on hydrous ferric oxide (HFO) bioreduction. Biodegradation 2003 14, 91-103.

(39) Biber, M. V.; dos Santos, Afonso, M.; Stumm, W. The coordination chemistry of weathering: IV. Inhibition of the dissolution of oxide minerals. Geochim. Cosmochim. Acta 1994, 58, 19992010.

(40) Urrutia, M. M.; Roden, E. E.; Fredrickson, J. K.; Zachara, J. M. Microbial and surface chemistry controls on reduction of synthetic Fe(III) oxide minerals by the dissimilatory ironreducing bacterium Shewanella alga. Geomicrobiol. J. 1998, 15, 269-291.

(41) Zachara, J. M.; Fredrickson, J. K.; Smith, S. C.; Gassman, P. L. Solubilization of Fe(III) oxide-bound trace metals by a dissimilatory Fe(III) reducing bacterium. Geochim. Cosmochim. Acta 2001, 65, 75-93.

(42) Haldar, M.; Mandal, L. N. Effect of Phosphorus and Zinc on the Growth and Phosphorus, Zinc, Copper, Iron and Manganese Nutrition of Rice. Plant Soil 1981, 59, 415-425.

(43) Wang, H. D.; Harris, W. G.; Yuan, T. L. Relation between phosphorus and iron in Florida phosphatic soils. Soil Sci. Soc. Am. J. 1991, 55, 554-560.

Received for review March 23, 2006. Revised manuscript received September 30, 2006. Accepted October 16, 2006.

ES060695P 